\title{
Gramsci e a concepção marxista de escola
}

Doutorando em Educação Brasileira pela Universidade Federal do Ceará

Sandra Cordeiro Felismino

Professora da Universidade Federal do Ceará

\section{Resumo}

$\mathrm{O}$ artigo tenciona demonstrar que a concepção gramsciana de escola não se reduz ao aparelho escolar convencional, mas engloba um conjunto de organismos do mundo do trabalho potencialmente formativos. Pretende, portanto, oferecer elementos categoriais que permitam recompor o conceito gramsciano de escola no corpo geral da crítica marxista.

Palavras-chave: Teoria Educacional Marxista; Revolução; Escola.

\begin{abstract}
The article demonstrates that the Gramscian conception of the school is not limited to conventional school unit, but includes a set of organizations in the world of work potentially formative. The aim, therefore, offer concepts that compose the Gramscian concept of school in the general body of Marxist criticism.
\end{abstract}

Keywords: Marxist Educational Theory; Revolution; School. 
$\mathrm{N}$ o quadro geral do pensamento pedagógico brasileiro, as idéias de Antonio Gramsci não somente ocupam lugar particular, como também são fonte de múltiplas interpretações, polêmicas e discussões ${ }^{1}$. Expressão eloqüente da tradição marxista, Antonio Gramsci ocupou-se ao longo de sua vida da análise das relações entre as condições objetivas do modo de produção capitalista e a organização cultural que movimenta o mundo ideológico, objetivando apreender as determinações histórico-sociais a serem consideradas na preparação da revolução proletária. Suas idéias são particularmente importantes para a Pedagogia porque em seu pensamento a Política assume validade pedagógica, isto é, na medida em que a formação de uma hegemonia de novo tipo pressupõe a elevação intelectual, política e cultural das massas trabalhadoras, a questão educativa emerge como problema fulcral em sua estratégia revolucionária.

A forte influência do pensamento de Gramsci no campo pedagógico brasileiro inicia-se a partir da segunda metade da década de 1970, materializando-se na década posterior em trabalhos científicos e políticos que traziam os conceitos de Estado, sociedade civil e hegemonia como referências teóricas basilares para a compreensão do papel que a organização escolar formal deveria assumir num contexto marcado pela ascensão e fortalecimento dos movimentos operários, bem como das lutas populares.

Esse quadro de efervescência da vida política brasileira produziu condições para recobrar a discussão educacional e pedagógica, mormente entre os educadores de esquerda. Neste contexto, educadores brasileiros, críticos das relações sociais capitalistas, no esforço de compreender o papel

\footnotetext{
1 De modo geral, no campo pedagógico brasileiro, autores filiados ao pensamento de Gramsci apresentam algumas idéias comuns, a saber: (i) fazem a crítica às análises de Louis Althusser acerca dos aparelhos ideológicos de Estado e do papel desempenhado pela ideologia dominante no sentido unilateral de garantia da reprodução das relações capitalistas de exploração, (ii) advogam, a partir de algumas categorias gramscianas - como hegemonia e sociedade civil - a necessidade de uma ação educativa escolar capaz de desarticular a ideologia dominante, e que venha a possibilitar a criação de uma contraideologia; (iii) afirmam o papel dos educadores como intelectuais orgânicos destinados a promover a "contra-hegemonia"; (iv) apregoam o papel da escola na formação de uma nova cultura (uma nova concepção do mundo).
} 
que a escola assume numa sociedade capitalista, passaram a questionar a crença na neutralidade da educação e a chamar a atenção para o fato de que a prática pedagógica escolar não se reduz a um conjunto de técnicas e métodos de ensino. Entrementes, tornou-se uma espécie de consenso a idéia de que o fenômeno educativo escolar não poderia mais ser analisado de forma abstrata e a-histórica, mas a partir de seus condicionantes econômicos, políticos e sociais. A prática educativa escolar, por conseguinte, passou a ser contextualizada e suas determinações buscadas para além do aspecto técnico. Destarte, buscar compreender, à luz do pensamento de Gramsci, o papel que a escola (na perspectiva da classe trabalhadora) assumia numa sociedade capitalista implicava recuperar o sentido atribuído por este pensador às categorias de Estado e sociedade civil.

Em nossa dissertação de mestrado procuramos demonstrar que categorias-chave da proposta de Gramsci (Estado, sociedade civil, hegemonia etc.) foram afastadas do campo teórico-prático do marxismo ${ }^{2}$. Observamos, sobretudo nos textos que foram produzidos no final da década de 1980 e início da década de 1990, certa tentativa de minimização da dimensão revolucionária do pensamento de Gramsci, o que se traduz a partir da ausência de categorias centrais, como revolução, luta de classes e partido revolucionário; bem como a existência de uma "fratura" no interior do corpus teórico gramsciano, isto é, a desconsideração dos escritos que marcam sua militância comunista. Sustentamos que a "destotalização" da obra de Gramsci mediante o deslocamento de suas categorias da luta revolucionária socialista com a qual ele estava comprometido dificultou o equacionamento de sua proposta político-pedagógica. Nesse sentido, a apropriação do pensamento gramsciano feita pelos educadores foi problemática porque operou, em grande medida, uma fratura no interior de seu corpus teórico. Percebemos que os autores, para tratar da problemática educacional, utilizam como referência exclusiva os textos do período da

2 OLIVEIRA, Thiago Chagas. Formação Política e Consciência de Classe no Jovem Gramsci (1916 - 1920). Universidade Federal do Ceará, Fortaleza, 2007. Ver capítulo II: "Considerações acerca da influência de Gramsci no campo pedagógico brasileiro". 
produção de Gramsci no cárcere. Os escritos carcerários, certamente, são os mais expressivos e têm mais densidade teórica. Há de se pesar, contudo, o fato de que a escrita cifrada de Gramsci, utilizada para driblar a censura fascista de Mussolini, possibilita uma multiplicidade de interpretações que oscilam, muitas vezes, entre perspectivas inconciliáveis. Isto, de certo modo, comprometeu a apropriação de seu pensamento, provocando desacordos intelectuais que, seguramente, resvalaram em questões vitais para a formação do pensamento pedagógico marxista brasileiro.

A apropriação seccionada do pensamento de Gramsci provocou consequiências teórico-metodológicas questionáveis para o emprego correto de suas idéias. Isto se expressa, por exemplo, quando o conceito de sociedade civil é deslocado das determinações estruturais da sociedade capitalista (produção de mais-valia, exploração da força de trabalho etc), assim como do papel que o Estado assume na regulação da ordem burguesa. Seu uso, assim, torna-se problemático a partir do momento em que é empregado para minimizar a centralidade da luta de classes na explicação do movimento histórico, bem como para dissolver a necessidade de superação da contradição entre capital e trabalho a partir da idéia vaga de "fortalecimento da sociedade civil"

Ressalte-se, ainda, que nos dias atuais o conceito de sociedade civil passa por uma ressignificação profunda. Sua utilização se presta a fins inteiramente exógenos ao campo ideopolítico marxista, como exemplo, para justificar o desaparecimento dos conflitos e das classes ${ }^{4}$. Isto é feito, em

\footnotetext{
${ }^{3}$ Franco Cambi, em sua História da Pedagogia, afirma que: "No mundo contemporâneo caracterizado pelo individualismo e pela dicotomia entre dominantes e dominados, [...] - , não é partindo da estrutura (a economia) que se pode transformar a realidade, mas sim operando em particular a partir da superestrutura (a ideologia, a cultura). Em torno de uma revolução da mentalidade é possível agregar diversas classes ou grupos sociais, interessados na mudança ("bloco histórico"), para construir uma "hegemonia" cultural e depois política (e não vice-versa), da qual o "Partido novo" (revolucionário e proletário, de massa e artífice da estratégia política visando ao exercício da hegemonia) é intérprete e avalista.(Grifos nossos, p.562-563).

${ }^{4}$ Peter Mayo, por exemplo, afirma que: "Dado o papel que Gramsci designa à classe operária industrial no processo revolucionário, pode ser argumentado que sua visão de transformação social é [...] "essencialista" ou, mais precisamente, "essencialista de classe". $\mathrm{E}$ mesmo na medida em que diz respeito à classe, ele enfoca principalmente o papel transformador de apenas uma das duas classes "subalternas" da Itália: o proletariado
} 
especial, pelos neoliberais e pós-modernos. As conseqüências práticas desse tipo de leitura para a luta política dos educadores são problemáticas, na medida em que a difusão e o emprego acrítico da noção de sociedade civil por entidades representativas dos trabalhadores, por exemplo, sinaliza para o perigo de que esteja se desenvolvendo um processo de coerção de novo tipo, ou seja, aquela coerção "exercida pela elite de uma classe sobre a própria classe, [que] passa a ser uma autocoerção, uma autodisciplina" (GRAMSCI, 1975 , p.962-963).

A conclusão a que chegamos sinaliza para a idéia de que as categorias gramscianas de Estado, sociedade civil, hegemonia e educação são utilizadas com os conteúdos quase que puramente liberais, que, quando não situados em aberta oposição ao campo teórico-prático do marxismo, se afastam enormemente de seus princípios basilares ${ }^{5}$. Com base nos escritos gramscianos que vão de 1916 a 1920, procuramos demonstrar que a necessidade de uma nova sociedade civil, expressão material e subjetiva de

industrial, em vez da classe camponesa (MAYO, 2004, p.99). Observe que o autor minimiza consideravelmente a validade analítica da noção de classe, descartando, assim, todo o peso da herança marxista nas formulações teóricas de Gramsci. A desconsideração do papel histórico de classe para a superação da sociedade capitalista esteriliza um dos princípios do marxismo, qual seja, a consideração segundo a qual a emancipação humana ocorrerá numa sociabilidade que, por via revolucionária, supere a propriedade privada e o trabalho assalariado.

5 A apreensão teórica do conceito gramsciano de sociedade civil pelos pedagogos brasileiros se deu mediante forte influência de Noberto Bobbio (1999). Esta interpretação, desenvolvida a partir da distinção conceitual operada por Gramsci com relação ao conceito de sociedade civil em Marx e Engels (1998), é problemática porque, além de operar uma falsa dicotomia entre sociedade civil e Estado, retira a importância da produção e da reprodução material da sociedade na compreensão da dinâmica histórica. Nessa perspectiva, o fator explicativo do movimento histórico passa a ser a um elemento da superestrutura, no caso da sociedade capitalista, a "sociedade civil" (compreendida erroneamente como uma esfera autônoma relativamente às determinações estruturais). A simplificação e radicalização desta interpretação de Gramsci subsidiam apropriações pedagógicas idealistas de suas idéias expressas, por exemplo, na crença da força social de uma escola crítica e transformadora. Em Escola, Estado e Sociedade, por exemplo, Bárbara Freitag (1980, p.126) diz que: "Para ele [Gramsci] é na sociedade civil (lugar de circulação das ideologias e de exercício da função hegemônica) que se trava, em certas constelações, a luta decisiva entre as classes dirigentes e as subalternas, e não na instância econômica ou estatal". A esse respeito, não deixar de ver também o terceiro capítulo do livro Gramsci e a escola, de Luna Galano Mochocvitch. Ressalte-se que, se na década de 1980 já existia certa propensão à substituição da luta de classes pelo conceito de sociedade civil, na década seguinte isto se efetivará a partir de três vetores: (i) pelo neoliberalismo; (ii) pelos críticos da sociedade do trabalho, como Clauss Offe e Jurgen Habermas, bem como pelo (iii) pósmodernismo. 
uma hegemonia de novo tipo, antagônica à lógica do capital, não significa o abandono da superação do antagonismo estrutural entre capital e trabalho. Em Gramsci, a formação de um novo bloco histórico tem origem no trabalho emancipado, ou seja, a partir de novas relações de produção e distribuição (DEL ROIO, 2005). Como estrutura e superestrutura/ teoria e prática não se separam, antes formam uma unidade dialética, a luta da classe trabalhadora contra o capital pode e deve ser potencializada por trabalhos pedagógicos voltados à formação e ao desenvolvimento de sua consciência de classe ${ }^{6}$. Destarte, a luta organizada contra o capital deixa de ser apenas econômico-política e passa a ser também uma luta cultural, na medida em que a necessidade de desvelamento da estrutura funcional capitalista se transforma em estímulo para o desenvolvimento intelectual dos trabalhadores.

As possibilidades formativas e pedagógicas em Gramsci, por isso, são equacionadas em função dos interesses de classe do proletariado e resolvidas como um problema de classe. Esta tese tem como corolário a noção de que em seu pensamento a educação possui uma dupla determinação: negativa, uma vez que não existem condições objetivas para a efetivação de uma educação voltada ao desenvolvimento integral da personalidade humana (omnilaterlaidade) numa sociedade que se erige a partir da valorização das necessidades de expansão indefinida do capital e não das necessidades humanas; mas, ao mesmo tempo, positiva, na medida em que o movimento contraditório da luta de classes entre capital e trabalho abre a possibilidade de desenvolvimento de ações pedagógicas e formativas que, geradas e desenvolvidas no âmbito da sociedade civil, contribuem para

\footnotetext{
${ }^{6}$ Esta noção, que se encontra presente nos escritos de Marx e Engels, se desenvolve no corpus teórico gramsciano. Segundo Marx e Engels (1998), à medida que os trabalhadores vão se organizando em associações, sindicatos e em partidos políticos, sua luta contra os capitalistas vai se fortalecendo; eles vão adquirindo consciência de sua força e, deste modo, vão se formando como classe antagônica ao capital. Eis aqui uma das dimensões daquilo que Gramsci chamou de processo catártico: "A estrutura da força exterior que esmaga o homem, que o assimila e o torna passivo, se transforma em meio de liberdade, em instrumento para criar uma nova iniciativa" (1975, p. 1244).
} 
a formação de um trabalhador de novo tipo, isto é, preparado para dar prosseguimento ao trabalho de construção do Estado socialista.

Outrossim, partimos da compreensão de que a concepção de uma hegemonia de novo tipo em Gramsci assenta-se numa dupla determinação: de um lado, o surgimento de uma massa revolucionária capaz de se preparar e se organizar para a gestão da nova sociedade; de outra parte, a necessidade de potencializar suas lutas contra o capital com iniciativas educativoculturais que permitissem aos trabalhadores a compreensão da totalidade do processo produtivo. Nos Quaderni del carcere, este processo se traduz na terminologia "reforma intelectual e moral", que aponta para a necessidade de unidade orgânica entre as forças operárias e camponesas e os intelectuais. Isto porque, na medida em que a reprodução do capital não exige apenas a renovação dos meios de trabalho, mas também a interiorização, mediante o desenvolvimento da educação burguesa (entendida em sentido amplo) ${ }^{7}$, dos valores e da moral necessária à reprodução social capitalista, Gramsci aposta, como resposta à dominação cultural capitalista e como parte integrante do processo de formação da consciência de classe, na necessidade de difusão do marxismo no seio da classe trabalhadora ${ }^{8}$.

É nesse contexto que achamos possível pensar a atuação da escola numa sociedade de classes. Faz-se necessário demarcar, antes de qualquer coisa, que as reflexões gramscianas sobre a escola não se reduzem ao aparelho escolar convencional. Não obstante as análises de Gramsci, acerca do papel desempenhado pela escola capitalista, serem ricas e instigantes, há

\footnotetext{
${ }^{7}$ Segundo Marx: "Não basta que haja, de um lado, condições de trabalho sob a forma de capital e, do outro, seres humanos que nada têm para vender além de sua força trabalho. Tampouco basta forçá-los a se venderem livremente. Ao progredir a produção capitalista, desenvolve-se uma classe trabalhadora que, por educação, tradição e costume, aceita as exigências daquele modo de produção como leis naturais evidentes" (Grifos nossos, 2003, p.851).

${ }^{8}$ A formação de uma hegemonia de novo tipo vincula-se organicamente ao papel que os intelectuais realizam no âmbito da sociedade civil, mormente no que diz respeito à atuação dos organismos responsáveis pela realização do consenso. Na compreensão de Gramsci (1975), os intelectuais assumem importância fundamental na criação, solidificação e conservação da hegemonia social e do governo político, na medida em que desempenham a função de difundir e conservar a concepção do mundo que atende aos interesses das classes dirigentes.
} 
de se lembrar que a relação pedagógica, como uma relação de hegemonia, não se circunscreve à dinâmica interna da sala de aula. No caderno número 10, numa nota intitulada Introduzione allo studio della fiosofia, Gramsci diz que:

[...] a relação pedagógica não pode ser limitada às relações especificamente "escolares", através das quais as novas gerações entram em contato com as antigas e absorvem suas experiências e seus valores historicamente necessários, "amadurecendo" e desenvolvendo uma personalidade própria, histórica e culturalmente superior. Esta relação existe em toda a sociedade no seu conjunto e em todo indivíduo com relação aos outros indivíduos, entre camadas intelectuais e não intelectuais, entre governantes e governados, entre elites e seguidores, entre dirigentes e dirigidos, entre vanguardas e corpos de exército $(1975, \mathrm{p} .1331)$.

Nessa passagem, podemos observar que Gramsci compreende a relação pedagógica para além de seu sentido estricto. Grosso modo, podemos dizer que ele a concebe como experiência coletiva de emancipação. A obra educativa dos bolcheviques para a elevação intelectual das massas e viabilização de sua participação na constituição do projeto revolucionário russo exemplifica, ainda que parcialmente, a idéia segundo a qual a relação pedagógica, como uma relação de hegemonia, não se restringe à interação professor-aluno. Ressaltem-se, ainda, suas reflexões acerca da necessidade imperiosa do capitalismo fordista de formar um novo tipo humano, adaptado às condições de trabalho, nutrição, habitação, costume etc., requerida pela vida na indústria e suas considerações sobre o fato de como tal preocupação, existente entre os industriais, se expressava nas iniciativas "educativas" (aspeado pelo próprio Gramsci) proposta nos livros dos ideólogos do novo industrialismo, como Henry Ford e André Phillip. Por fim, há de se destacar a tarefa educativa e formativa atribuída por Gramsci ao Estado,

[...] que sempre tem o fim de criar novos e mais altos tipos de civilização, de adequar a "civilização" e a moralidade das mais vastas massas populares às necessidades de desenvolvimento contínuo do aparelho econômico de produção, portanto, de elaborar também fisicamente tipos novos de humanidade (1975, p.1576). 
Quando Gramsci assevera a importância da escola na desarticulação da ideologia dominante e de elaboração de uma forma superior de cultura (nova concepção do mundo), ele compreende o significado de escola em sentido ampliado, situando-se no próprio terreno da hegemonia como síntese teórico-prática do movimento revolucionário de transformação social que exige organicidade, seja do pensamento filosófico, seja da solidez organizativa e de centralização cultural. Ressalte-se também o fato de que sua concepção da relação entre teoria e prática é outra: fecunda, densa e distante das comuns considerações de pedagogos escolares. Em conformidade com o principio de unidade entre teoria e prática exposta por Marx na II Tese sobre Feuerbach, portanto, crítico ao tratamento escolástico da questão, Gramsci concebe essa 'unidade como devir histórico, como ponto de chegada do movimento universal da classe operária, mediante o qual as contradições específicas do modo de produção capitalista serão superadas.

À luz do pensamento de Gramsci, portanto, podemos acentuar que a escola não se reduz ao aparelho escolar convencional, mas engloba um conjunto de organismos oriundos do mundo do trabalho potencialmente formativos: escolas de partido, instituições de elaboração da vida cultural, como revistas e jornais operários (a célebre experiência de L'Ordine Nuovo, por exemplo), meios para organizar e difundir determinados tipo de cultura, como clubes, associações culturais, institutos de cultura popular etc. O equacionamento acerca do papel que a organização escolar formal assume na difusão de uma nova concepção de mundo capaz de responder aos interesses históricos postos pela luta dos trabalhadores passa, necessariamente, pela compreensão de seus vínculos com as inúmeras possibilidades educativas oriundas do mundo do trabalho, tais como: as experiências revolucionárias de superação do capitalismo, as lutas empreendidas pelos trabalhadores contra os burgueses na defesa de seus interesses (greves); o papel educativo dos conselhos de fábrica; o papel informativo e formativo exercido pelos jornais operários etc. Entender as possibilidades da escola na perspectiva da classe trabalhadora exige 
compreender que sua atuação se vincula organicamente à atuação formativa dos diversos instrumentos de luta da classe trabalhadora (partidos, sindicatos, associações, conselhos de fábrica, movimentos camponeses etc).

É importante destacar, contudo, o fato de que em Gramsci o sentido lato conferido à atividade e à organização escolar não dilui a especificidade da instituição escolar como espaço e tempo de educação e formação da nova geração nem secundariza o seu papel para o processo de socialização e aquisição dos conhecimentos acerca das leis naturais e das leis produzidas socialmente pela atividade do homem. A organização escolar formal, na qualidade de aparelho privado de hegemonia ${ }^{9}$ e por meio de seus intelectuais orgânicos, pode vir a assumir um papel tático para a conquista do poder pelas classes subalternas. Empregamos o adjetivo tático porque compreendemos que a escola só pode exercer suas funções genuinamente formadoras (a transmissão adequada do saber historicamente acumulado pelos homens como parte integrante de sua formação omnilateral) numa sociedade que vá para além da lógica do capital. Enquanto vivermos numa forma societária radicalmente dividida entre aqueles que pensam e os que executam, alicerçada sob a lógica da exploração do homem pelo homem, isto é, numa sociedade que se erige a partir da valorização das necessidades de expansão indefinida do capital e não das necessidades humanas, a escola está destinada a servir à reprodução das relações sociais capitalistas. Eis porque, para Gramsci, a verdadeira face da escola, sob a lógica do capital, se resume a "uma incubadora de pequenos monstros aridamente instruídos por um mestre, sem idéias gerias, sem cultura geral, sem alma, mas somente com olho infalível e mão firme” (1980, p.671).

Em La prima pietra (1916), Gramsci faz questão de deixar claro que a atuação da instituição escolar não é a-histórica, por conseguinte, não pode ser analisada de forma abstrata. No capitalismo, ela serve muito mais aos interesses de produção e reprodução das relações sociais capitalistas do que

\footnotetext{
${ }^{9}$ Em seu caderno 12, Gramsci trata da sociedade civil como "conjunto de organismos vulgarmente chamado 'privados' ". É interessante ressaltar que o provável sentido da colocação das aspas na palavra privado parece sugerir um questionamento a própria natureza da sociedade civil e de seus organismos na sociedade capitalista.
} 
aos de elevação do conhecimento e formação de uma consciência superior, sobretudo da classe trabalhadora. Diz Gramsci:

Que as classes dirigentes e os intelectuais que estão a seu serviço vão impor as impor as grandes massas de trabalhadores rurais e urbanos um plano de educação que venha a formar um estado de consciência e uma mentalidade em conformidade com seus propósitos de dominação é algo demasiadamente natural, inclusive, toda a história das instituições pedagógicas confirmam isto (1980, p.642).

Ressalte-se, contudo, que o reconhecimento da negatividade da organização escolar formal não significa desconsiderar, sem mais, suas possibilidades na criação e difusão de uma concepção de mundo que atenda aos interesses históricos dos trabalhadores, ainda que sob os marcos do capitalismo. Se, organicamente vinculada ao movimento operário de transformação do real (seja no sentido industrial, seja no senso político), a escola convencional pode vir a auxiliar na divulgação de uma nova concepção do mundo. Nos Quaderni, Gramsci diz:

Com o seu ensino, a escola luta contra o folclore, contra todas as sedimentações tradicionais de concepções do mundo, a fim de difundir uma concepção mais moderna, cujos elementos primitivos e fundamentais são dados pela aprendizagem da existência de leis naturais como algo objetivo e rebelde, às quais é preciso adaptar-se para dominá-las, e de leis civis e estatais, produto de uma atividade humana, que são estabelecidas pelo homem e podem ser por ele modificadas tendo em vista seu desenvolvimento coletivo; [...] (1975, p.1540).

Quando esse for o caso, para que essa função não seja realizada de forma idealista e romântica, faz-se necessária sua vinculação com um projeto revolucionário e sua articulação com os diversos organismos culturais formativos oriundos do mundo do trabalho, em especial, com o partido revolucionário, na luta pela elevação intelectual, moral e cultural das massas. O partido revolucionário, segundo Gramsci, pelo fato de reunir indivíduos que demonstram clara e forte vontade de construir a sociedade socialista e por potencializar a vontade coletiva das massas, é a mola propulsora da revolução socialista. Uma de suas funções residiria na 
preparação da classe trabalhadora para a gestão social, mediante uma ação política voltada para a formação da consciência de classe das massas. Para tanto, o trabalho pedagógico de propagação do marxismo no seio da classe trabalhadora, processo intitulado por Gramsci de "preparação espiritual da revolução", é absolutamente fundamental ao quefazer revolucionário.

Acompanhando os escritos pré-carcerários de Gramsci, observamos que, no célebre artigo Uomni o macchine? (1916), sua primeira observação com relação à problemática educacional reside justamente na incapacidade do PSI em elaborar um programa escolar que se diferencie daquele proposto pelos burgueses ${ }^{10}$. Em 1916, isto é, 16 anos antes das reflexões carcerárias acerca do princípio educativo da escola unitária, Gramsci sustenta a idéia de que o programa de educação do proletariado deveria ser gestado a partir dos organismos que o próprio proletariado já constituiu em defesa de seus interesses. Daí a idéia de que a escola deveria ser mantida sob o controle dos organismos políticos proletários (sindicatos, associações, conselhos de fábrica, partidos políticos, movimentos populares...). Segundo Gramsci, “O problema da educação é o máximo problema de classe, por isso, não pode ser resolvido a não ser sob o ponto de vista de classe, que é o único que permite a avaliação proletária das instituições sociais e das leis.” (1980, p.643).

Se, na perspectiva das classes dominantes, a ação pedagógica, articulada à ação política dos partidos que lhes representam, atende a seus interesses, numa perspectiva revolucionária, a ação pedagógica escolar deve estar organicamente vinculada ao ideário e ao modo de ação do partido revolucionário, que, por um lado, seria o grande responsável pela formação dos intelectuais orgânicos à classe trabalhadora, e, por outro, o organizador e realizador de uma reforma intelectual e também moral entre as massas, “o que significa criar o terreno para um ulterior desenvolvimento da vontade coletiva nacional popular no sentido de efetuar uma forma superior e total de civilização moderna" (GRAMSCI, 1975, p.1560).

${ }^{10}$ Ver Gramsci, 1980, p.669. 
Por vontade coletiva nacional-popular, entenda-se superação dos resíduos corporativos da classe trabalhadora, exercício real da hegemonia sobre toda a sociedade, ou seja: elaboração de um grau de consciência capaz de permitir "uma iniciativa política que englobe a totalidade dos estratos sociais de uma nação, capaz de incidir sobre a universalidade diferenciada do conjunto das relações sociais" (COUTINHO, 1999, p.169). No que tange a sua constituição, tarefa genuína do moderno príncipe, Gramsci indica a necessidade de um trabalho de elaboração de uma nova cultura, superior e universal, para a qual a escola poderia desempenhar um papel importante. Organicamente vinculada aos movimentos sociais que lutam pela constituição de um novo ordenamento social, a escola poderia vir a desempenhar um papel importante, na medida em que sua ação contribuísse para a difusão de uma nova concepção de mundo

liberta de toda magia ou bruxaria, [que] fornece o ponto de partida para o posterior desenvolvimento de uma concepção histórica, dialética, do mundo, para a compreensão do movimento e do devir, para a avaliação da soma de esforços e sacrifícios que o presente custou ao passado e que o futuro custa ao presente, para a concepção da atualidade como síntese do passado, de todas as gerações passadas, que se projeta no futuro (GRAMSCI, 1975, p.1541).

Considerando que o "moderno príncipe" é, por excelência, o grande elaborador e difusor dessa nova concepção, somos levado a afirmar que Gramsci articula dialeticamente as possibilidades contra-hegemônicas exercidas pela escola ao ideário e ao modo de atuação do partido revolucionário. A ação cultural formativa, por isso, compreendida como parte integrante de um projeto revolucionário, assume importância fundamental na luta pela abolição da sociedade de classes. Em acordo com a idéia de Marx, contida na Crítica da Filosofia do Direito de Hegel Introdução, segundo a qual a teoria se transforma em força material tão logo se apodere das massas, Gramsci considerava absolutamente fundamental que as massas se apoderassem da filosofia da práxis (marxismo) como instrumento de compreensão e de transformação da realidade. 
Recolocar o papel da instituição escolar na elaboração de uma contra-ideologia revolucionária, portanto, significa compreender que sua atuação se relaciona, ainda que de forma mediata, com as diversas possibilidades educativas contidas no próprio processo produtivo. Fazer essa disjunção - o que significa o rompimento com a unidade entre teoria e prática - significa atribuir à instituição escolar uma força que ela não tem.

\section{Referências bibliográficas}

BOBBIO, Norbeto. Ensaios sobre Gramsci e o conceito de sociedade civil. Tradução de Marco Aurélio Nogueira e Carlos Nelson Coutinho. São Paulo: Paz e Terra, 1999.

CAMBI, Franco. História da Pedagogia. Tradução de Álvaro Lorencini. São Paulo: Editora UNESP, 1999.

COUTINHO, Carlos Nelson. Gramsci. Um estudo sobre seu pensamento político. Nova edição revista e ampliada. Rio de Janeiro: Civilização Brasileira, 1999.

COUTINHO, Carlos Nelson. Prefácio. In: NEVES, Lúcia Maria Wanderley. A nova pedagogia da hegemonia: estratégias do capital para educar o consenso (org.) São Paulo: Xamã, 2005.

DEL ROIO, Marcos. Os prismas de Gramsci: a fórmula politica da frente única (1919 - 1926). São Paulo: Xamã, 2005.

FREITAG, Bárbara. Escola, Estado e sociedade. 4.ed. São Paulo: Moraes, 1980.

GRAMSCI, Antonio. Quaderni del carcere. Torino: Nuova Universale Einaudi, 1975.

GRAMSCI, Antonio. Cronache Torinesi (1913 - 1917). Torino: Einaudi, 1980.

MARX, Karl. O capital: crítica da economia política (livro I - Tomo II). Tradução de Reginaldo Sant'Anna. 19a ed. Rio de Janeiro: Civilização Brasileira, 2003.

MARX, Karl; ENGELS, Friedrich. Manifesto Comunista. Tradução Álvaro Pina. São Paulo: Boitempo, 1998.

MAYO, Peter. Gramsci, Freire e a Educação de adultos: possibilidades para uma ação transformadora. Tradução Carlos Alberto Silveira Netto Soares. Porto Alegre: Artmed, 2004.

MOCHCOVITCH, Luna Galano. Gramsci e a escola. São Paulo: Ática, 1988. 